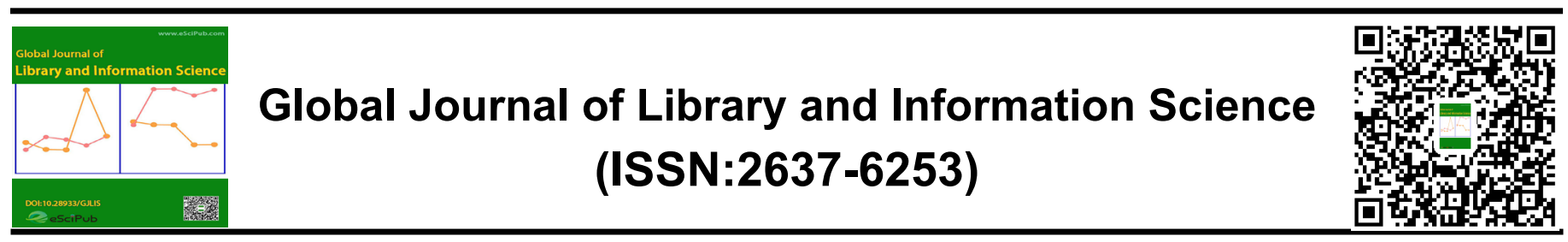

\title{
A Preliminary Study of the Role of University Library in the Age of Fragmented Reading
}

\section{Limeng Che}

Inner Mongolia University Library, No. 235 university west road, Hohhot, Inner Mongolia,China.

\begin{abstract}
In China, the development and the wide usage of mobile Internet and intelligent terminal devices have exerted a huge impact on people's reading patterns. Reading has entered the "Fragmentation Era", and "Fragmented Reading" has become the major pattern of reading.This paper expounds the advantages and disadvantages of fragmented reading and the influence of the major trend of fragmented reading on college students' reading and what role should university library play and what reading service should it provide in the age of fragmented reading.
\end{abstract}

Keywords: Fragmented Reading; Reading Services; University Libraries
*Correspondence to Author:

Limeng Che

Inner Mongolia University Library, No.235 university west road, Hohhot, Inner Mongolia, China.

How to cite this article:

Limeng Che.A Preliminary Study of the Role of University Library in the Age of Fragmented Reading. Global Journal of Library and Information Science, 2019, 2:6.

\section{eScîPub}

eSciPub LLC, Houston, TX USA.

Website: http://escipub.com/ 


\section{Introduction}

Released by the Chinese academy of press and publication in April 2018, the 15th national national reading survey report shows: in 2017 the comprehensive reading rate of adult citizens in mainland China was $80.3 \%$, through a variety of $\mathrm{m}$ edia, including books, newspapers, journals and digital publications, $73.0 \%$ of comprehensive reading is digital reading or online reading, by devices such as mobile phones, electronic readers, Pad reading.

The percentage of digital reading by various electronic reading devices of adult citizens is 59.7 in 2017 , and $71.0 \%$ of adults read on their mobile phones while $63.4 \%$ of them read by WeChat. From the perspective of people's exposure to different media, the average daily mobile phone contact time of Chinese adults is 80.43 minutes. and internet access time is 60.70 minutes; The average person spends 27.02 minutes a day reading WeChat.

According to the data above, the ready access to mobile Internet and portable electronic readers such as smart phones, ipads and kindles has changed the reading pattern of people in China to "Fragmentated Reading". The most distinctive feature of information on the mobile Internet is fragmentation, in other words "in pieces", which makes the reading behavior of people tend to be more and more fragmented.

"Fragmented reading" refers to a kind of reading pattern of which the reading content is fragmentated, incomplete and intermittent ${ }^{[1]}$, by mobile $d-$ evices such as smart phones, e-book readers and other intelligent electronic terminal devices or blog, WeChat, mobile APP and other platforms through the Internet. Fragmented reading is very different from traditional reading, the most distinctive characteristic of fragmentation of reading time and reading content. Fragmented reading doesn't require any special condition, e$x c e p t$ for access to mobile smart devices, readers can get fragmentated information on the Internet anytime and anywhere. While the traditional reading need a relatively long period of time and the relatively quiet environment. From the perspective of reading effect, fragmented read- ing is also very different from traditional reading. For its reading content is short and easy to understand, while traditional reading requires high concentration of readers to fully understand the reading material.

College students are a group with the highest acceptance of new media technology and new intelligent devices. For them, fragmented reading has gradually become the main form of reading, taking up a large amount of their reading time and becoming an indispensable part of their study and life. In this case, it is of great research value how fragmented reading influences college students' reading and how university libraries should provide reading services to college students in the era of fragmented reading.

\section{Features, Advantages and Disadvatages of Fragmented Reading}

\subsection{Characteristics of Fragmented Reading} 2.1.1 Fragmentation of Reading Content

Fragmented reading is mainly in "pieces" of time, and the content is often fragmentary, lacking coherence .As people's fragmented reading is often through WeChat, microblog, mobile phone App, etc., the information of fragmented reading is often in short pieces, wide coverage, and the content is relatively simple and of casual entertainment.

\subsubsection{Fragmentation of Reading Time}

Fragmented reading of people is often during fragmentary time when taking buses, subways, in lines or in other pieces of time. The reading time is relatively scattered and random, so people can only browse the reading content quickly and are unlikely to read deeply.

\subsection{Advantages and Disadvantages of Frag- mented Reading}

\subsubsection{Advantages of Fragmented Reading}

In the era of fragmented reading, as the knowledge and information published on smart electronic devices can be shared by all at the same time, everyone can participate in the making a comment and communicating with others, and eeveryone enjoys the opportunity to read. People can access all kinds of information at any time and anywhere, in fragments of time. Without leaving their homes, people can know the world by rnal-of-library-and-information-science/ 
reading short, timely messages with a wide variety of content, and readers can choose what they are interested in.

Fragmented reading makes use of small pieces of time, which can bring us a lot of benefits while increasing the utilization of time. The characteristics of speed, timeliness, interaction and making full use of spare time are all advantages that traditional reading does not have.

For college students, by fragmented reading, they can make full use of their spare pieces of time to open their eyes, broaden their scope of $k$ nowledge, as well as communicate with other readers without the limit of time and space, this will make their learning more efficient.

\subsubsection{Advantages of Fragmented Reading}

The content of fragmented reading is often very brief, and the information provided to the readers tend to be very incomplete, which can only contain a little knowledge of something, so these information can not give the readers deep understanding of the content, the knowledge is only skin deep. So ,For college students, spending too much time on fragmented reading is harmful for them to improve their ability of systematic a$\mathrm{d}$ independent thinking and might cause thinking inertia, and fragmentation crisis ${ }^{[2]}$.

For Chinese people who spent a relatively less average reading time, the wide spread fragmented reading might reduce their deep reading time. Intensive reading requires continuous time, high concentration and deep thinking. In fragmented reading, it is difficult for people to enter the state of deep reading, which will greatly reduce the $h$ arvest of reading.

Era of fragmentation create favorable conditions for college students to read and have made it possible for them to get access to new and diverse knowledge and information, but because of their lack of the ability of independent thinking and good eyes for valuable information, so in the intermingled and fragmentated information environment, and some junk information may have bad effect on them, "The situation now in mainland China is that fragmentated reading has gradually became the main form of reading of college students, if thing go on like this, in the long run, it might cause reading and thinking degradation of college students, and is very harmful for them to learn systematically and think deeply.

\section{Reading Services of Uiversity Lbraries in the Era of Fragmented Reading}

\subsection{Role of University Libraries in the Era of Fragmented Reading}

Fragmented reading is not only the reading mode of contemporary college students, but also their learning mode. The main interests of college students' fragmented learning are hobbies, skill learning and examinations. Library is the center of information and knowledge, as well as a place for information literacy training and reading guidance, which also has the functions of information resource development and dissemination. University libraries should play two roles for college students.

\subsubsection{A Guide to Fragmented Reading}

Powerful media technology of today, enables students to access to vast amount of diverse information of wide coverage, but those information usually lacks screening and filtering, and are intermingled with good and bad, so some unhealthy, illegal or negative information is very likely to lead to students' cognitive biases or have negative effect on them.

In this case, as the information collection and distribution center, university libraries in colleges and universities should shoulder the responsibility of guiding university students on their fragmentated reading.

The use of new media tools, such as WeChat public library or WeChat subscription number of library, can provide guidance for college students to their reading and means to communicate with each other as well as share knowledge and ideas.

\subsubsection{A Provider of Fragmented Reading Ser- vices}

Library service roles in college students' fragmented reading and learning age are device provider, network provider and reading content provider.

To do a good job in fragmented reading services, university libraries should focus on the following aspects of the work: First, building of a good mo- 
bile network access and technical support. Second, recommending beneficial mobile reading contents to the fragmented reading of students. Third, designing training program on college students's network information literacy to improve their. Forth, Using the benefits of WeChat or mobile library service to the full to provide readers with various content of high quality information, professional learning materials or extended data and through the integration of library human resources and information resources with these new media to build communication and sharing platform for them.

In a word, organizing reading promotion camoaign of high quality, around the student's attention hot spot is the core of reading service.

\subsubsection{A Teacher of Information Literacy}

Information literacy refers to a person's comprehensive ability to correctly recognize their own information needs and effectively find, obtain, process, evaluate and use information through reasonable ways. The amount of reading that libraries can provide is limited compared to the vast amount of Internet information.

To make reasonable use of fragmented information, people must learn to find and identify the information they need, so as to avoid getting lost in the ocean of information. The library staff who have better information literacy, should open courses to help improve readers' information literacy.

Due to the different levels of readers' needs, the library should pay attention to the levels and pertinence in the training. Scientific speed-reading method, Internet information search and screening training can further improve readers' reading level and improve their reading efficiency. Basic methods of using such methods as basic reading content search training for people with poor reading ability and introduction to emerging reading media are also required.

These training courses can help college studentts overcome obstacles in their reading process, lower the reading threshold and stimulate their interest in reading. At the same time, libraries should also help readers develop good reading habits, cultivate their ability of formulating rea- sonable reading strategies, and let readers learn to make reasonable use of a variety of reading methods to meet the needs of reading to improve reading effect and experience.

\section{Services of University Libraries in the Era of Fragmented Reading}

The era of new media has greatly changed the $r$ eading mode of college readers, and fragmented

reading has become the mainstream reading $\mathrm{m}$ ode, which brings new opportunities and challenges to the reading service of college libraries, they must learn to make use of new technology, innovate the work of reading service, and make transformation in both service concept and technology.

\subsection{Ways of Library Information Services}

Nowadays, college readers are more and more accustomed to Internet search and fragmented reading, so what libraries should do is provide a variety of service modes that can provide fragmented reading, change the passive service mode into active service mode, and make library services more suitable to the needs and habits of readers.

\subsubsection{Mobile Library Services}

At present, many colleges and universities in China have mobile library services. Mobile library is actually the product of the wide application and popularization of new media technology and mobile intelligent devices, which enables readers to query, browse online, download or obtain bibliography and digital resources of the library by means of document transmission no matter where they are. Mobile libraries conform to the fragmented reading habits of readers and provide university readers with access to the official resources.

\subsubsection{Library WeChat Platform Services}

WeChat is currently the most widely used social service platform. The "fragmented" information content released by the micro-reading platform which has the immediacy and interactivity and enables personalized selection and free use of information, is very responsible for the fragmented reading habits of readers. University librarians should provide professional answers and 
guidance for readers online on WeChat public account, which can help readers better adapt to today's reading habits, and can improve the quality of information services by information push and online consulting services.

\subsection{Guidance Service by Information Push}

University libraries should provide readers with systematic, comprehensive and high-quality information resources, integrate human and collection resources, as well as books/digital materials and network information, and combine them with WeChat public account platform, and push various new book recommendation or book review and other guided information extracted by the library to readers.In this way, readers can be guided and their main reading platform of fragmented reading gradually becomes the library reading platform.

In fragmentated reading age, university libraries must comply with the trend, change their service pattern and content, and most importantly shouId play a role of introducing readers to in-depth and complete reading of good books. ${ }^{[3]}$

\section{References}

1. Liu Dina, Research on fragmented reading in the era of mobile Internet[D]. Liaoning: Liaoning University, 2016

2. Shuxian Luo, The influence of fragmented reading on information service innovation of university libraries in the era of mobile Internet[J]. Intelligence Exploration, vol.5, pp.102-104, 2016.

3. Zhu Ligong The present situation and development of library micro-reading service. Lantai World. vol.32, pp.75-76, 2014. 